\title{
Tischchen deck dich
}

\section{Erhard Taverna}

Dr. med., Mitglied der Redaktion

Der wundersame Tisch aus Grimms Märchen gehört, wie der Goldesel und der Knüppel aus dem Sack, zum allgemeinen Sprachgebrauch. Das begab sich allerdings zu einer Zeit, als das Wünschen noch geholfen hat. Was kommt bei zehn Milliarden Menschen auf den Tisch? Die Expo in Mailand Feeding the Planet, Energy for Life bot eine nationale Auslegeordnung der Probleme und Lösungsversuche. Werden die grossen Konzerne, wie Monsanto und Syngenta, oder die Kleinbauern genügend Nahrung produzieren, können wir unseren gewohnten Lebensstil beibehalten oder wird der Hunger global endemisch? Wie immer, wenn es um die Ernährung geht, wird es politisch. Wer im grossen Stil Lebensmittel anbieten kann, übt eine enorme Macht aus. Von Plato und Epikur bis zu Nietzsche und Feuerbach hat sich die Philosophie mit den kulinarischen Grundbedingungen irdischer Glückseligkeit befasst. Der erste sprach vom «Hungerbauch als einem wilden Tier», der zweite, zu Unrecht als Hedonist verschrien, empfahl seine be-

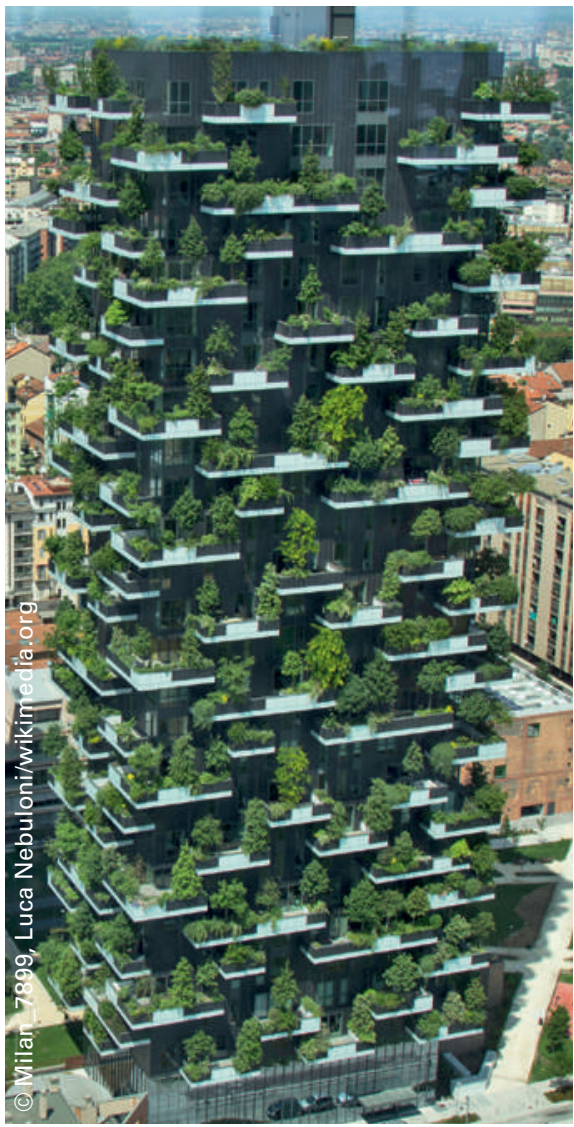

Fanal des urban farming: bosco verticale, die bepflanzten Mailänder Wohntürme. scheidenen Suppen. Zarathustra preist die "grosse Vernunft des Leibes», der Hegelschüler fordert soziale Gerechtigkeit: «Wo du vor Hunger, vor Elend keinen Stoff im Leibe hast, da hast du auch in deinem Kopfe, deinem Sinne und Herzen, keinen Grund und Stoff zur Moral.» Bertolt Brecht findet dafür in der Dreigroschenoper die Kurzformel: «Erst kommt das Fressen, dann kommt die Moral.» Immer wieder gelang es mit technischen Mitteln, die Agrarproduktion zu steigern, doch jede Entwicklung hatte ihren Preis. Stickstoff überdüngt die Böden, die grüne Revolution verbraucht Unmengen von Wasser, Herbiziden und Pestiziden. Ohne Chemie wird heute kein Tisch mehr gedeckt. Die Risiken sind inbegriffen. E-Stoffe können Hyperaktivität bei Kindern auslösen, Verpackungen enthalten Verbindungen, die den Stoffwechsel schädigen, die industrielle Produktion bewirkt Allergien und Unverträglichkei- ten, was hypochondrische Reaktionen provoziert, die wiederum der Markt ausbeutet. Das vermeintliche Schlaraffenland ist mit Ratgebern und Profitjägern kontaminiert, die Ich-AG von Angebot und übertriebenen Erwartungen überfordert. «Die moderne Freiheit durchquert den Magen des Selbst», urteilt Wilhelm Schmid, der Philosoph der Lebenskunst. Er fordert eine «neue Diätetik, gut lebbare Kompositionen und volle Entfaltung der Sinne».

Doch woher sollen diese Kompositionen kommen? Das Ei ohne Huhn ist schon da, Fleisch aus dem Labor noch zu teuer, Essen aus dem Drucker keine Alternative. Pflanzliche Würste und Lupinen als Sojaersatz sind Vorboten der neuen Esskultur. Die Knappheit der Ressourcen macht Visionäre und Tüftler erfinderisch. Die neue Lebensmittelverordnung des Bundes will ab 2016 Grillen, Mehlwürmer und Heuschrecken zulassen. Der bosco verticale, die neuen Wohntürme in Mailand, wirkt wie ein Fanal des urban farming. Die Städte, bereits Wohnort für die Hälfte aller Erdbewohner, sollen sich selber ernähren. Hors sol hat eine grosse Zukunft, denn wer in der Vertikalen bei Kunstlicht Gemüse und Früchte anbaut, braucht keinen Boden und erntet ökologischer. So zumindest die Hoffnung. Die neuen Spielräume setzen auf Gartenstädte unter Mitbeteiligung der Bürger und Bürgerinnen. Damit werden Herrschaftsstrukturen tangiert, denn Raumplanung, Bodenrecht und bisherige Marktmonopole sind herausgefordert. Satte sind bessere Untertanen. Doch Roms antikes Rezept «Brot und Spiele» können selbst Billigelektronik und junk food nicht langfristig kopieren, denn Fehlernährung belastet alle Gesundheitssysteme. Vordenker wie der Philosoph Bernhard Taureck werben für eine vegane Lebensweise. Sein «Manifest des veganen Humanismus» setzt aus ethischen, ökologischen und medizinischen Gründen auf eine «Tier-Entnutzungsethik». Ausschliesslich pflanzliche Ernährung, keine Tierprodukte zur Bekleidung, keine Tierexperimente, keine Zoo- und langfristig auch keine Haustiere. Eine Utopie mit guten Argumenten, die auf viele Schwachstellen unserer menschenzentrierten Denkschablonen und Gewohnheiten hinweist. Die eingereichte Initiative für einen Spekulations-Stopp auf Nahrungsmittel wird es an der Urne schwierig haben. Die Welternährung bleibt eine Herausforderung, die auf allen Gebieten riesige Anstrengungen erfordert. Im Märchen kommt am Ende das entwendete Tischchen wieder an den rechtmässigen Besitzer zurück. Hoffen wir, dass es uns auch so ergeht. 